\title{
Atrial fibrillation after Coronary Artery Bypass Surgery with and without Cardiopulmonary Bypass
}

\author{
Md. Rezaul Karim 1 , Tawfiq Ahmed², Shahriar Moinuddin ${ }^{1}$, Tariq Ahmed Chowdhury ${ }^{3}$, \\ Moshfequre Rahman Khan ${ }^{4}$ \\ ${ }^{1}$ Department of Cardiac Surgery, NICVD, ${ }^{2}$ Department of Cardiac Surgery, Sir Salimullah \\ Medical College, ${ }^{3}$ Department of Cardiology, NICVD, ${ }^{4}$ Department of Cardiology, Shahid \\ Tazuddin Ahmed Medical College
}

\begin{abstract}
Keywords:
Atrial

Abstract:

fibrillation, Ischaemic heart

disease, Coronary Artery Bypass Surgery, Cardiopulmonary bypass.

Background:Atrial fibrillation (AF) is the most common postoperative supraventricular arrhythmi. $20 \%$ to $40 \%$ of patients have AF after coronary artery bypass operation (CABG).Arrhythmia of all grades may occur due to cardiopulmonary bypass $(C P B)$ and injuries inflicted during operativeprocedures. Thus it has been proposed that $C A B G$ surgery would be safer if $C P B$ could be avoided.

Methods:Total 60 patients who underwentCABG were selected for the study and divided in two groups. Group A: 30 patients with Off-pump CABG (OPCAB) and Group B: 30 patients with On-pump CABG. 12 lead ECG was done at morning on the day of surgery, after surgery \& when any arrhythmia are noted for at least 7 days. Morbidity of patients like arrhythmia and hospital mortality were recorded and compared during the first week after surgery.

Results:Off-pump group (group-A) had less incidence of post-operative AF than on-pump group(group-B) $(10 \%$ vs $40 \%)$. Postoperative blood requirement, total operative time, the period of mechanical ventilation,ICU stay and total postoperative hospital stayis significantly shorter in off-pump than in on-pump group of patients.

Conclusion: This study clearly demonstrates that off pump CABG procedure is associated with less incidence of AF. Therefore OPCAB procedure for myocardial revascularization is clearly justified whenever feasible.
\end{abstract}

(Cardiovasc. j. 2018; 10(2): 171-179)

\section{Introduction:}

Postoperative arrhythmias are common complication after cardiac surgery. Incidence of postoperative $\mathrm{AF}$ varies between 10\%-40\% during the first postoperative week. ${ }^{1} \mathrm{AF}$ is the most common supraventricular arrhythmia following cardiac surgery. It ranges from $28 \%$ $54 \%$ of patients. ${ }^{2}$ Incidence of atrialarrhythmia including AF after open heart surgery is between $20 \%$ and $50 \% .{ }^{3} 20 \%$ to $40 \%$ of patients have $\mathrm{AF}$ after coronary artery bypass operation. ${ }^{4}$ These variations in the incidence of $\mathrm{AF}$ depend on the patient population studied, type ofcardiac surgery, the definition of the arrhythmia and the duration of observation period. . $^{5}$

After CABGthe etiology of AF is unknown, but may due to -unprotected ischemia, multi- dosecardioplegic solution administration with high potassium

concentration, atrial dilation or inadequate atrial protection and postoperative pericarditis. Certain patients develop supraventricular arrhythmia related to the

preoperative accumulation of catecholamines in intramyocardial axon.Additional risk factors areadvanced age, chronic obstructive pulmonary disease (COPD), thyrotoxicosis, hypomagnesemia,hypokalemia, prolonged aortic cross-clamp periods, and discontinuationof preoperative beta- blockers. ${ }^{2}$

Cardiopulmonary bypass is a technique by which the pumping action of the heart \& thegas exchange functions of the lung are replaced

Address of Correspondence: Dr. Md. Rezaul Karim, Department of Cardiac Surgery, NICVD, Dhaka, Bangladesh. e-maildrrezanicvd@gmail.com 
temporarily by a mechanical device- the pumpoxygenator attached to a patient's vascular system. Although some temporary dysfunction oforgans \& systems is occasionally the sequelae of present technique; CPB has become anindispensable technique for most cardiac surgical procedure. ${ }^{7}$ After 1968 , CABG with CPB was widely adopted and has becomewellestablished treatment modalities for patients with CAD. ${ }^{8}$ However therehas been increasing evidence that CPB may be responsible for some of the morbidities associated with CABG surgery.

Cardiovascular subsystem injuries due to CPB are numerous. Arrhythmia of all grades and all types of heart block may occur due to CPB and as a result of injuries inflicted during operativeprocedures. Of course electrolyte imbalance and metabolic changes after CPB may also beresponsible for these arrhythmia. These may reduce the cardiac output and can cause cardiac failure. ${ }^{9}$ In-patients with low cardiac reserve; arrhythmia may give rise to sudden cardiac death. Thus it has been proposed that CABG surgery would be safer if CPB could be avoided. ${ }^{10}$

In recent years, off-pump coronary artery grafting (OPCAB) has emerged as an alternative method for conventional coronary artery bypass grafting (CCABG). Evidence suggests that avoidance of CPB significantly reduces morbidity with marked decrease in post-operative complications i.e. stroke, various degree of neurological dysfunction, low output syndrome,

different types of arrhythmia like atrial fibrillation, respiratory and renal dysfunction, bleedingand need for transfusion, release of myocardial enzymes and other biochemical markers of injury or inflammations, postoperative ventilation time, ionotropic support, ICU \& total hospital stay. 7, 9, 11

The advent of OPCAB brought with it the hope and the expectation that there would be a striking lower incidence of postoperative AF, because many of the hypothesized causes of AF could be eliminated. The early results reported an incidence of AF in OPCAB to be as low as

$5 \%, 12$ which is contradictory to other off pump studies with incidence of $\mathrm{AF} 30 \%$ as for
Conventional CABG. ${ }^{13}$ So we decided to conduct the study to compare the incidence of postoperative AF between OPCAB \& CCABG.

\section{Methods:}

This prospective, nonrandomized clinical study was conducted at Department of Cardiac Surgery, NICVD, Dhaka from July 2015 to July 2016. Total 60 patients who will undergo CABG were selected for the study divided in two groups, Group A: 30 patients Off-pump (OPCAB)group, where operation was done without cardiopulmonary bypass and Group B: 30 patients On-pump (CCABG) group, where operation was done under cardiopulmonary bypass. Patient pre-operatively in sinus rhythm admitted for elective CABG were included in the study.Patients were excluded from the study if there is emergency CABG, CABG with valve surgery, CABG with congenital Cardiac Surgery, awake CABG, conversion CABG, on-pump beating $\mathrm{CABG}$, patient with electrolyte imbalance, history of recent MI and thyroid dysfunction.

Detailed history of each patient under study, important and relevant findings on thorough physical examinations and investigations were recorded. Particular emphasis was given on history of taking beta blockers and other antiarrhythmic drugs and past history of myocardial infarction, congestive heart failure, diabetes mellitus, hypertension and chronic renal failure.

After completing CABG with or without cardiopulmonary bypass, patients were taken into intensive care unit (ICU). Patient will be monitored in ICU continuously with cardiac monitor \&thereafter in the postoperative ward by symptoms and rhythm strip ECG done 8 hourly for 7 days. Estimation of Serum electrolytes was done daily for four days after surgery. 12 lead ECG was done at morning on the day of surgery, after surgery \& when any arrhythmia are noted for at least 7 days. Ventilation time, duration of inotrope support and ICU stay were recorded in hours and compared between groups. Morbidity of patients like arrhythmia were recorded and compared between groups. In hospital mortality were recorded and compared between groups. All 
patients who survived were followed up for seven days. During follow up they were evaluated clinically and with the help of ECG. Statistical analyses will be carried out by using SPSS 23.0(Statistical Package for the Social Sciences by SPSS Inc., Chicago, IL, USA, 2015).

\section{Results:}

This study is intended to see the incidence of atrial fibrillation after OPCAB in comparison to Conventional CABG. The mean age of group A patients was $52.6 \pm 8.8$ years \&of group B patients was $50.3 \pm 7.8$ years ranging from 33 to 65 years. It was found that highest percentage $(40 \%$ vs $36.7 \%$ in group A and group B respectively) had age between $41-50$ years. Analysis revealed that no statistically significant between 2 groups regarding age of the patients. There was no significant difference between the groups in terms of sex. But shows that there is a male dominance among the patients group A (Male 96.7\% against female 3.3\%) and group B (Male 93.3\% against female $6.7 \%$ ).

Chest pain, dyspnea, palpitation \&fatigue were the main presenting symptoms. Chest pain was the most predominant symptom in both the groups (93.3\% vs. 90\%) followed by dyspnea (46.6\% vs. 56.6\%)in group A and group B respectively but the differences were not statistically significant for any symptom.

In this study smoking was the most common risk factor(Group A 70\% vs Group B 66.6\%, p=0.781) followed by hypertension. Regarding hypertension and dyslipidemia, Group A and Group B were almost similar (54.16 \% vs. 58.33\%, $\mathrm{p}=0.77 ; 30 \%$ vs. $23 \%, \mathrm{p}=0.559)$.Prevalence of diabetes mellitus were also similar in both groups
(Group A 41.17\% vs. Group B 41.17\%, p=1). There was no statistically significant difference in the prevalence of risk factors between the groups.

Out of 60 patients, $50 \%$ and $46.7 \%$ received beta blocker in group -A \& group -B respectively. Calcium blocker were $16.7 \%$ and $20 \%$, no antiarrhythmic drugs were taken by $9 \%$ and $9 \%$ in group A \& group B respectively and this drugs were also continued postoperatively. There was no statistically significant difference between the groups in chi-square test (Table I).

The mean percent of ejection fraction was $55.4 \pm 7.3$ in group A patients and $56.3 \pm 5.9$ in group B patients. Analysis showed that no statistically significant mean difference was found between two groups of patients (pe"0.05), it was found that most of the patients have left ventricular ejection fraction $(50 \%-60 \%)$.

Left anterior descending (LAD ) \& Left circumflex ( LCX) were the predominant vessels involved in both the groups (90\% vs $85 \%$ \& 70 $\%$ vs $73.3 \%$ ) followed by right coronary artery $(\mathrm{RCA})$, posterior descending artery, diagonal \& left main coronary artery ( LMCA) . Analysis revealed that there was no statistically significant difference of involvement of individual coronary vessel in between the groups. In the group A, maximum patients $(66.7 \%)$ were found triple vessel disease, double vessels were $33.3 \%$ and single vessel involvement was none. Whereas in group-B patients, maximum patients (70\%) were found triple vessel disease, double vessels were $30.0 \%$ and single vessel involvement nil. The mean number diseased vessels were $2.67 \pm 0.48$ and $2.7 \pm 0.47$ in group A and group B respectively. Analysis revealed that no

Table-I

Distribution of patients according to their antiarrhythmic drug received.

\begin{tabular}{lcccccc}
\hline \multirow{2}{*}{$\begin{array}{l}\text { Drug received before } \\
\text { operation }\end{array}$} & \multicolumn{2}{c}{ Group A } & & \multicolumn{2}{c}{ Group B } & p value \\
\cline { 2 - 3 } & No. & $\%$ & & No. & $\%$ & \\
\hline Beta blocker & 15 & 50 & & 14 & 46.7 & $0.796^{\text {NS }}$ \\
Ca $^{++}$channel blocker & 5 & 16.7 & & 6 & 20 & $0.739^{\text {NS }}$ \\
Other antiarrhythmic & 1 & 3.3 & & 1 & 3.3 & \\
Not taken & 9 & 30 & & 9 & 30 & \\
\hline Total & 30 & 100 & & 30 & 100 & \\
\hline
\end{tabular}

Group A: OPCAB (Off Pump)

Group B: CCABG (On Pump) 
statistically significant difference was found between two groups of patients ( $p>0.05)$ in terms of number of diseased vessels.

Out of 60 patients, maximum patients were found having 03 grafts in both groups. In groupA $60 \%$ were found 03 grafts, $33.3 \%$ were found 02 grafts \& $6.6 \%$ were found 04 grafts. Whereas in group-B 56.6\% were found 03 grafts, $30 \%$ were found 02 grafts \& 13.3\% were found 04 grafts. No patient was found with single graft. Analysis revealed that there was no statistically significant difference in between the two groups of patients $(p>0.05)$ in terms of number of grafts.

Electrolytes status of the study population before operation revealed no difference.(Table: II)

In the operative day ( POD 0 ) the mean sodium was $143.3 \pm 2.5$ and $144.1 \pm 2.5$, potassium was $4.2 \pm 02$ and $3.9 \pm 0.1$, calcium was $9.2 \pm 0.5$ and $9.6 \pm 06$, chloride was $102.5 \pm 1.7$ and $104.2 \pm 16 \&$ bicarbonate was $25.5 \pm 1.2$ and $25.3 \pm 1.3$ in groupA \& group-B respectively. The mean difference was not statistically significant $(p>0.05)$ between group A and group B patients. In the postoperative day 1 (POD1) the mean sodium was $144.1 \pm 2.3$ and $146.1 \pm 2.4$, potassium was $3.8 \pm 0$ 4 and $4.2 \pm 0.2$, calcium was $8.5 \pm 0.4$ and $8.1 \pm 0.4$, chloride was $101.4 \pm 1.8$ and $101.2 \pm 1.5 \&$ bicarbonate was $23 \cdot 2 \pm 1.1$ and $24.2 \pm 1.2$ in groupA \& group-B respectively. The mean difference was not statistically significant $(p>0.05)$ between group A and group B patients. In the postoperative day 2 (P0D2) the mean sodium was $140.7 \pm 2.9$ and $142.1 \pm 2.7$, potassium was $4.2 \pm$ 0.3 and $3.9 \pm 0.2$, calcium was $9.9 \pm 0.3$ and $8.9 \pm$ 0.5 , chloride was $103.4 \pm 1.5$ and $102.2 \pm 1.4 \&$ bicarbonate was $25.6 \pm 1.1$ and $24.1 \pm 1.3$ in groupA \& group-B respectively. The mean difference was not statistically significant $(p>0.05)$ between group A and group B patients. In the postoperative day 3 ( POD 3 ) the mean sodium was $134.8 \pm 2.6$ and $143.1 \pm 2.6$, potassium was $3.9 \pm$ 0.2 and $3.8 \pm 0.1$, calcium was $8.6 \pm 0.6$ and $9.4 \pm$ 0.3 , chloride was $104.5 \pm 1.6$ and $103.1 \pm 1.5$, bicarbonate was $23.9 \pm 1$.1 and $27.4 \pm 1.3$ in groupA \& B respectively. The mean difference was not statistically significant $(p>-0.05)$ between group A and group B patient. But the mean magnesium was $1.8 \pm 0.1,1.8 \pm 0.2,1.7 \pm 0.2 \& 1.8$ \pm 0.2 in POD O, POD 1 , POD 2 \&POD 3 respectively in group- $A$ and the mean magnesium was $1.1 \pm 0.2,1.1 \pm 0.2,1.0 \pm 0.2$ \& $1.2 \pm 0.2$ in POD O, POD1, POD 2, \& POD 3 respectively in group- $\mathrm{B}$. Analysis revealed that there was statistically significant difference in between the two groups of patients $(p>0.05)$ in terms of magnesium status after operation. So the analysis revealed that magnesium status is nearly similar in OPCAB group before \& after operation. But the magnesium status is significantly lower in CCABG group after operation. (Table: III).

Comparison of Total operative time shows the mean operative time in OPCAB group was $(5.1 \pm 0.51)$ hours and the mean operative time in

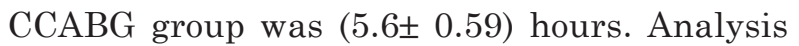
revealed that there was statistically significant difference in between the two groups $(p<0.05)$ in terms of total operative time.

Assessment of peri operative MI done by ECG changes \& blood level of CK-MB was done during

Table-II

$\mathrm{Na}^{+}, \mathrm{K}^{+}, \mathrm{Ca}^{++}, \mathrm{Mg}^{++}, \mathrm{CI}^{-}$and $\mathrm{HCO}_{3}^{-}$status before operation.

\begin{tabular}{lccc}
\hline & $\begin{array}{c}\text { Group A } \\
(\text { mean } \pm \text { SD })\end{array}$ & $\begin{array}{c}\text { Group B } \\
(\text { mean } \pm \text { SD })\end{array}$ & p value \\
\hline $\mathrm{Na}^{+}(\mathrm{mmol})$ & $141.9 \pm 2.9$ & $143.1 \pm 2.7$ & 0.138 NS \\
$\mathrm{K}^{+}(\mathrm{mmol})$ & $3.9 \pm 0.2$ & $3.8 \pm 0.1$ & $0.397 \mathrm{NS}$ \\
$\mathrm{Ca}^{++}(\mathrm{mg})$ & $8.5 \pm 0.4$ & $8.1 \pm 0.4$ & $0.945 \mathrm{NS}$ \\
$\mathrm{Mg}^{++}(\mathrm{mEq} / \mathrm{L})$ & $1.6 \pm 0.1$ & $1.7+0.2$ & $0.162 \mathrm{NS}$ \\
$\mathrm{Cl}^{-}(\mathrm{mmol})$ & $101.4 \pm 1.8$ & $101.2 \pm 1.6$ & 0.805 NS \\
$\mathrm{HCO}_{3}-(\mathrm{mmol})$ & $23.2 \pm 1.1$ & $24.2 \pm 1.2$ & $0.807 \mathrm{NS}$ \\
\hline
\end{tabular}

Group A: OPCAB (Off Pump)

Group B: CCABG (On Pump) 
Table-III

$\mathrm{Na}^{+}, \mathrm{K}^{+}, \mathrm{Ca}^{++}, \mathrm{Mg}^{++}, \mathrm{CI}^{-}$and $\mathrm{HCO}_{3}{ }^{-}$status after $\mathrm{CABG}$.

\begin{tabular}{|c|c|c|c|}
\hline & $\begin{array}{c}\text { Group A } \\
(\text { mean } \pm S D)\end{array}$ & $\begin{array}{c}\text { Group B } \\
(\text { mean } \pm S D)\end{array}$ & $\mathrm{p}$ value \\
\hline \multicolumn{4}{|c|}{$\overline{\mathrm{Na}^{+}(\mathrm{mmol})}$} \\
\hline POD 0 & $143.3 \pm 2.5$ & $144.1 \pm 2.5$ & $0.289 \mathrm{NS}$ \\
\hline POD 1 & $144.1 \pm 2.3$ & $146.1 \pm 2.4$ & $0.954 \mathrm{NS}$ \\
\hline POD 2 & $140.7 \pm 2.9$ & $142.1 \pm 2.7$ & $0.144^{\mathrm{NS}}$ \\
\hline POD 3 & $134 \pm 2.6$ & $143.1 \pm 2.6$ & $0.769^{\mathrm{NS}}$ \\
\hline \multicolumn{4}{|c|}{$\mathrm{K}^{+}(\mathrm{mmol})$} \\
\hline POD 0 & $4.2+0.2$ & $3.9 \pm 0.1$ & $0.542^{\mathrm{NS}}$ \\
\hline POD 1 & $3.8 \mathrm{ëX} 0.4$ & $4.2+0.2$ & $0.469 \mathrm{NS}$ \\
\hline POD 2 & $4.2+0.3$ & $3.9+0.2$ & $0.660^{\mathrm{NS}}$ \\
\hline POD 3 & $3.9 \pm 0.2$ & $3.8 \pm 0.1$ & $0.554^{\mathrm{NS}}$ \\
\hline \multicolumn{4}{|c|}{$\mathrm{Ca}^{++}(\mathrm{mg})$} \\
\hline POD 0 & $9.2 \pm 0.5$ & $9.6 \pm 0.6$ & $0.452^{\mathrm{NS}}$ \\
\hline POD 1 & $8.5 \pm 0.4$ & $8.1 \pm 0.4$ & $0.303^{\mathrm{NS}}$ \\
\hline POD 2 & $9.9 \pm 0.3$ & $8.9 \pm 0.5$ & $0.120^{\mathrm{NS}}$ \\
\hline POD 3 & $8.6 \pm 0.6$ & $9.4 \pm 03$ & $0.799 \mathrm{NS}$ \\
\hline \multicolumn{4}{|c|}{$\mathrm{HCO}_{3}-(\mathrm{mmol})$} \\
\hline POD 0 & $25.5 \pm 1.2$ & $25.3 \pm 1.3$ & $0.529 \mathrm{NS}$ \\
\hline POD 1 & $23.2 \pm 1.1$ & $24.2 \pm 1.2$ & $0.242^{\mathrm{NS}}$ \\
\hline POD 2 & $25.6 \pm 1.1$ & $24.1 \pm 1.4$ & $0.608^{\mathrm{NS}}$ \\
\hline POD 3 & $23.9+1.1$ & $274 \pm 1.3$ & $0.383^{\mathrm{NS}}$ \\
\hline \multicolumn{4}{|c|}{$\mathrm{Cl}^{-}(\mathrm{mmol})$} \\
\hline POD 0 & $102.5 \pm 1.7$ & $104.2 \pm 16$ & $0.874^{\mathrm{NS}}$ \\
\hline POD 1 & $101.4 \pm 1.8$ & $101.2 \pm 1.5$ & $0.554^{\mathrm{NS}}$ \\
\hline POD 2 & $103.4 \pm 1.5$ & $102.2 \pm 1.4$ & $0.923^{\mathrm{NS}}$ \\
\hline POD 3 & $104.5 \pm 1.6$ & $103.1 \pm 1.5$ & $0.326^{\mathrm{NS}}$ \\
\hline \multicolumn{4}{|c|}{$\mathrm{Mg}^{++}(\mathrm{mEq} / \mathrm{L})$} \\
\hline POD 0 & $1.8 \pm 0.1$ & $1.1 \pm 02$ & $0.001^{\mathrm{S}}$ \\
\hline POD 1 & $1.8 \pm 0.2$ & $1.1 \pm 0.2$ & $0.001^{\mathrm{S}}$ \\
\hline POD 2 & $1.7 \pm 0.2$ & $1.0 \pm 0.2$ & $0.001^{\mathrm{S}}$ \\
\hline POD 3 & $1.8 \pm 0.2$ & $1.2+0.2$ & \\
\hline
\end{tabular}

Group A: OPCAB (Off Pump) POD - Post-operative Day

Group B: CCBG (On Pump)

post-operative period. No patient developed ECG changes suggestive of perioperative MI. The mean level of CK-MB on arrival at ICU was although much higher in on pump group (28.05 \pm $7.01 \mathrm{U} / \mathrm{L})$ compared to that in off pump group $(12.65 \pm 6.68 \mathrm{U} / \mathrm{L})$, it sharply declined to $15.05 \pm$ $4.87 \mathrm{U} / \mathrm{L})$ on $1^{\text {st }} \mathrm{POD}$ and became almost

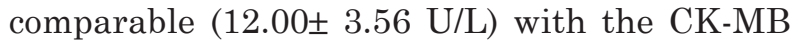
in off pump group $(9.75 \pm 4.16 \mathrm{U} / \mathrm{L})$ on $2^{\text {nd }} \mathrm{POD}$ ruling out evidence of perioperative MI. (Table: IV) (Fig: 1).

Several post-operative variables have been compared between groups such as amount of

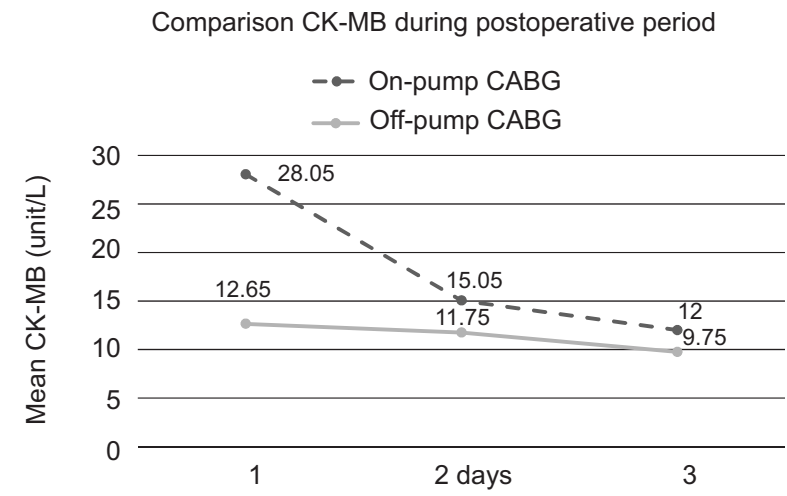

Fig.-1: Comparison CK-MB during postoperative period. 
blood required at ICU during post-operative period, mechanical ventilation time, ICU-stay and total post-operative hospital stay. The mean blood requirement in off pump patients during postoperative period was $1.5 \pm 0.14$ units and that in on-pump patients was $2.80 \pm 0.32$ units. Mean ventilation period in off pump group was $7.55 \pm$ 0.58 hours and that in on-pump group was 16.5 \pm 0.45 hours. In our study, the average ICUstay period in off-pump group was $37.3 \pm$ 8.62hours and that in on-pump was $68.2 \pm 4.75$ hours. Total postoperative stay in hospital averaged $9.25 \pm 0.25$ days in off-pump group and $10.60 \pm 0.33$ day in on pump group. Thus the mean period of mechanical ventilation, ICU- stay period, total post-operative hospital stay and amount of blood required at ICU during postoperative period all were significantly greater $(\mathrm{p}<0.05)$ in on pump group as opposed to off pump group.(Table: V)

Comparison of postoperative incidence of $\mathrm{AF}$ of the study population was done. In group A patients, $10.0 \%$ developed AF; whereas among group B patients, 40\% developed AF. Analysis revealed that statistically significant difference was found between two groups of patients $(p<0.05)$ in terms of post-operative atrial fibrillation after CABG. It appears that off-pump group (group- A) has less incidence of postoperative AF than on-pump group (group-B). Highest incidence of post-operative AF were at POD1 \& POD 2 in both off-pump and on-pump groups.(Table: VI) (Fig: - 2).

No patient of the any of the groups died during surgery or post-operative period.

Table-IV

Assessment of perioperative myocardial infarction.

\begin{tabular}{lccc}
\hline Blood level of CK-MB during & \multicolumn{2}{c}{ Group } & p value \\
\cline { 2 - 3 } postoperative period & $\begin{array}{c}\text { Off-pump CABG } \\
\text { (mean } \pm \text { SD) }\end{array}$ & $\begin{array}{c}\text { On-pump CABG } \\
\text { (mean } \pm \text { SD) }\end{array}$ & \\
\hline CK-MB on arrival at ICU (U/L) & $12.65 \pm 6.68$ & $28.05 \pm 7.01$ & $0.001^{\mathrm{S}}$ \\
CK-MB on POD1 (U/L) & $11.75 \pm 6.52$ & $15.05 \pm 4.87$ & $0.030^{\mathrm{S}}$ \\
CK-MB on POD2 (U/L) & $9.75+4.16$ & $12.00 \pm 3.56$ & $0.028^{\mathrm{S}}$ \\
\hline
\end{tabular}

Group A: OPCAB (Off Pump)

Group B: CCABG (On Pump)

Table-V

Comparison of post-operative variables between groups.

\begin{tabular}{lccc}
\hline Post operative variables & \multicolumn{2}{c}{ Group } & pvalue \\
\cline { 2 - 3 } & $\begin{array}{c}\text { Off-pump CABG } \\
\text { (mean } \pm \text { SD) }\end{array}$ & $\begin{array}{c}\text { On-pump CABG } \\
\text { (mean } \pm \text { SD) }\end{array}$ & \\
\hline Blood required at ICU (Units) & $1.5 \pm 0.14$ & $2.80 \pm 0.32$ & $0.001^{\mathrm{S}}$ \\
Mechanical ventilation time (hours) & $7.55 \pm 0.58$ & $16.5 \pm 0.45$ & $0.001^{\mathrm{S}}$ \\
ICU-stay (Days) & $37.3 \pm 8.62$ & $68.2 \pm 4.75$ & $0.001^{\mathrm{S}}$ \\
Total hospital stay (Days) & $9.25 \pm 0.25$ & $10.60 \pm 0.33$ & $0.001^{\mathrm{S}}$ \\
\hline
\end{tabular}

Group A: OPCAB (Off Pump)

Group B: CCABG (On Pump) 
Table-VI

Distribution of patients by incidence of $A F$ in study population.

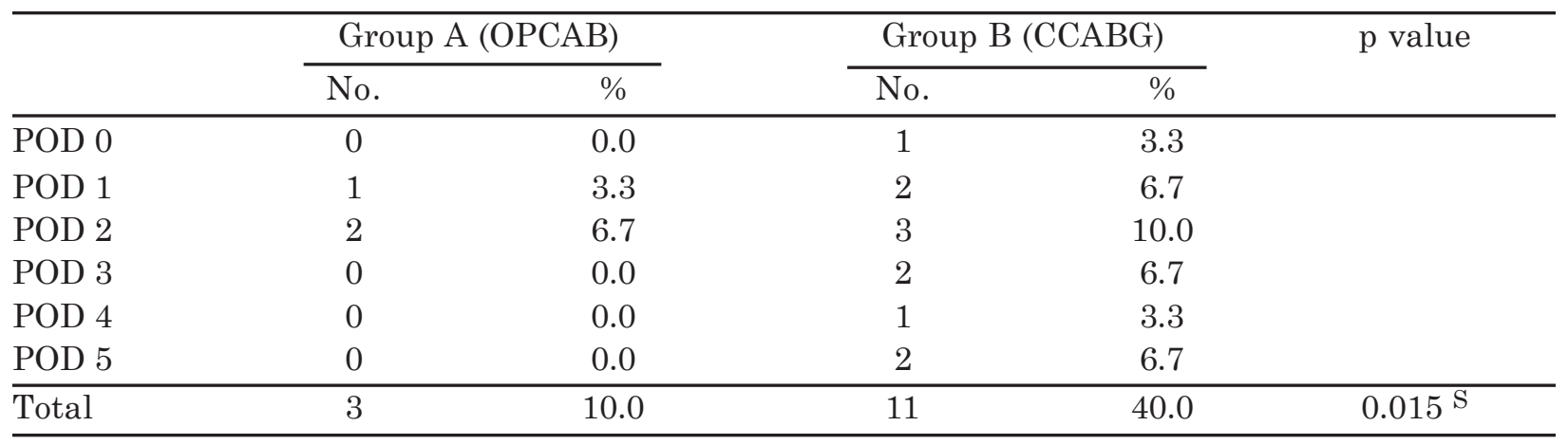

Group A: OPCAB (Off Pump)

Group B: CCABG (On Pump).

POD- Post operative day.

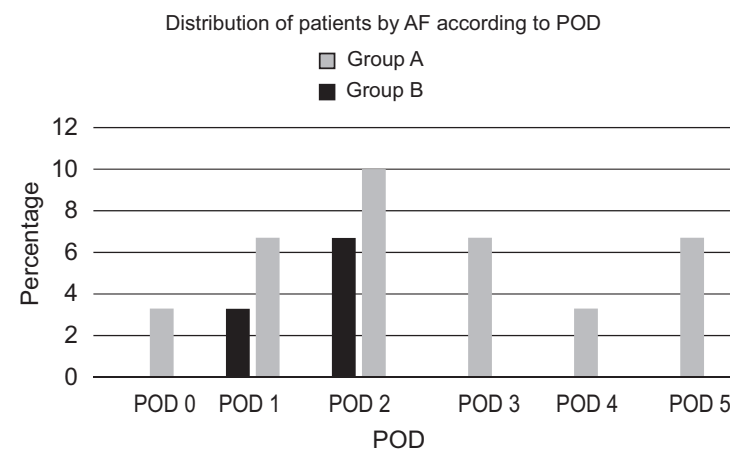

Fig.-2: Distribution of patients by AF according to $P O D$.

\section{Discussion:}

The first CABG (on-pump) surgery was done at NICVD, Bangladesh, in 1985. OPCAB surgery is being performed since 1997 in NICVD and subsequently in other cardiac centers in Bangladesh. This study was conducted at Department of Cardiac Surgery, NICVD, Dhaka from July 2015 to July 2016. 60 patients were selected for this study, of them 30 were- Off pump (OPCAB) group - A, where operation was done without cardiopulmonary bypass while other 30 were On-pump (CCABG) group - B, where operation was done under cardiopulmonary bypass.

The mean ages of off-pump and On-pump group of patients were $(52.6 \pm 8.8)$ years and $(50.3 \pm 7.8)$ years respectively which is not statically significant. It was found that highest percentage (40\% vs $36.7 \%$ in group A and group B respectively) had age between $41-50$ years. This result was more or less similar to other series. ${ }^{13}$
In this study out of 60 patients, $95.0 \%$ were male and $5.0 \%$ were female, with male and female ratio was 19:1. In group A 96.7\% and group B $93.3 \%$ were male and the rest $3.3 \%$ and $6.7 \%$ were female respectively. Analysis revealed that no statistically significant difference was found in regarding sex, so both sexes were equally distributed. Like many other series of CABG surgery male patients were predominant in this study but male female ratio was much higher in this series. This finding suggests atherosclerotic coronary artery disease is more prevalent in male than in female. ${ }^{11,14-17}$

Chest pain was the predominant symptom in both the groups. Distribution of common risk factors of coronary artery disease (CAD) such as smoking, diabetes mellitus, hypertension, hyperlipidemia, family history of CAD demonstrates that all risk factors were almost uniformly distributed in both the groups. These results confirm to that of Vargas and his colleagues. Smoking and hypertension were the more prevalent risk factors.

Patients taking antiarrhythmic drugs were continued in the post-operative period. Analysis revealed that no statistically significant difference was found between two groups of patients $(p>0.05)$. These findings closely correlate with the study carried out by Hazelrigg and his colleagues. ${ }^{18}$

As regards to the number of coronary artery involvement both groups included only double and triple vessel diseases. In Off-pump group $33.3 \%$ cases had double vessel disease and $66.7 \%$ 
case had triple vessel disease. In On-pump group, $30 \%$ patients had double vessel disease and 70\% patients had triple vessel disease. But this difference was not statistically significant between Group A and Group B. The preoperative cardiopulmonary functional status was compared using left ventricular ejection fraction ( $\mathrm{EF} \%)$, FVC andFEV1. The difference was not statistically significant.

The above findings showed that the preoperative difference regarding age, sex, risk factors of CAD and cardiopulmonary functional status were similar in the study groups. So these features should have no significant influence on postoperative outcome. These preoperative patient characteristic were comparable with the study series of Boyd and his colleagues. ${ }^{19}$

Electrolytes status of the study population was not statistically significantly different between group A and group B patients. Electrolytes status of the study population after operation revealed that magnesium status is nearly similar in OPCAB group before \& after operation. But the magnesium status is significantly lower in CCABG group after operation.

Comparison of preoperative variable between groups demonstrates that total operative time in off-pump group (5.1 \pm 0.51 hours) is significantly less $(p<0.05)$ than that of on-pump group $(5.6 \pm$ 0.59 hours) The mean operative time is proportionately slightly more in this series than that observed in the study carried by Haase and his colleagues. ${ }^{17}$

In group A maximum patients (60\%) were treated with 3 grafts, 2grafts in $33.3 \%$, 4 grafts in $6.6 \%$. Whereas in group-B patients, maximum patients $(56.6 \%)$ were treated with 3 grafts, 2 grafts in $30 \%$ and 4 grafts in $13.3 \%$ of the patients. No statistically significant difference was found between two groups of patients $(p>0.05)$ in terms of number of grafts.

Several post-operative variables have been compared between groups such as amount of blood required at ICU during post-operative period, mechanical ventilation time, ICU-stay and total post-operative hospital stay. The mean blood requirement in off pump patients during postoperative period was $1.5 \pm 0.14$ units and that in on-pump patients was $2.80 \pm 0.32$ units. Total transfusion requirement in group-A was much less is supported by many studies. ${ }^{17,}{ }^{20}$ Mean ventilation period in off pump group was $7.55 \pm$ 0.58 hours and that in on-pump group was 16.5 \pm 0.45 hours. This shows that ventilation time was significantly higher in on-pump group. This findings closely correlate with the study carried out by Ascione and his colleagues, ${ }^{20}$ but this is much lower than that in the series of Shenib and his colleagues ${ }^{21}$ suggesting a trend towards early extubation in our institution. In our study, the average ICU-stay period in off-pump group was $37.3 \pm 8.62$ hours and that in on-pump was $68.2 \pm 4.75$ hours. This finding is somewhat proportional to but higher than the value observed in several studies. ${ }^{17},{ }^{21}$ Total postoperative stay in hospital averaged $9.25 \pm$ 0.25 days in off-pump group and $10.60 \pm 0.33$ day in on pump group. This finding closely correlates with the study carried out by Shenib and his colleagues and Hasse and his colleagues. ${ }^{17,21}$ But this is proportionately higher than found in series of Hoff and his colleagues. ${ }^{22}$ Thus the mean period of mechanical ventilation, ICU- stay period, total postoperative stay in hospital and amount of blood required at ICU during post-operative period all were significantly greater in on pump group as opposed to off pump group. All these reflect definite clinical advantage as well as favorable outcome associated with off pump group of patients. No patient in either group developed ECG changes such as significant new $Q$ wave and regression of $R$ wave greater than $25 \%$.Average CK-MB release during immediate and early postoperative period in off pump group of patient was much lower than found in on pump group of patients. No patient of either group showed sustained high rise of CK-MB.

In group A patients, 10\% developed AF. In group B, 40\% of patients developed AF. Analysis revealed that statistically significant difference was found between two groups of patients $(p=<0.05)$ in terms of post-operative atrial fibrillation after CABG. This finding closely correlate with the study carried out by Galloway and his colleagues and Ascione and his colleagues, ${ }^{12,20}$ suggesting less incidence of postoperative AF in off-pump group. Highest 
incidence of post-operative AF was at POD1\& POD 2 in both off- pump and on-pump groups. . This findings closely correlate with the study carried out by Fusterand his colleagues. ${ }^{3}$ This reflect definite clinical advantage as well as favorable outcome associated with off-pump group of patients in terms of post-operative incidence of $\mathrm{AF}$.

\section{Conclusion:}

This study clearly demonstrates that OPCAB procedure is safe and is associated with some better outcome including lesser incidence of atrial fibrillation. In addition to cardio-pulmonary bypass, cardioplegia content and its pattern of administration, prolonged aortic cross clamping, longer duration of operation time, electrolyte imbalances, age-related atrial atrophic changes, increased amount of blood transfusion and prolonged ventilation time might also contribute to the development of atrial fibrillation. Therefore OPCAB procedure for myocardial revascularization is clearly justified whenever feasible.

\section{Conflict of Interest - None.}

\section{References:}

1. Ommen SR, Odell JA, Stanton MS. Atrial arrhythmias after cardiothoracic surgery. N Engl J Med 1997; 336 : 1429- 1434.

2. Williams JB, Milano CA, Smith PK. Critical Care for the Adult Cardiac Patient. In: Sellke FW, Nido PJ \& Swanson SJ. Eds. Sabiston \& Spencer Surgery of the Chest.9th ed.Philadelphia: Elsevier Science, Inc,2016:1026-1050.

3. Fuster V, Ryden LE, Gibbons RJ, Antman EM, Klei WW, et al.ACC/AHA/ESC Guidelines for the Management of Patients With Atrial Fibrillation. J Am Col Cardiol 2001; 38(4): 1266iv.

4. Greenbarg MD, Katz NM, Luliano S, Tempesta BJ, SolomonAJ. CardiacRhythm Disturbance. In: Kouchoukos NT, Blackstone EH, Hanley FL, Kirklin JK. Eds. Kirklin/ Barratt-Boys Cardiac Surgery. 4th ed. Philadelphia: Elsevier Saunders, Inc, 2013: 698-741.

5. Frost L, Molgaard H, Christiansen EH, Hjortholm K, Paulsen PK, Thomsen PE. Artrial Fibrillation and flutter after coronary artery bypass surgery: epidemiology, risk factors and preventive trails. Int J Cardiol1992; 36(3): 253261.

6. January CT, Wann LS, Alpert JS, Calkins H, Cigarroa JE, Cleveland JC, et al. AHA/ACC/HRS guideline for the management of patients with atrial fibrillation: a report of the American College of Cardiology/American Heart Association Task Force on Practice Guidelines and the Heart Rhythm Society. Circulation 2014; 130: e199-e267.

7. Toeg HD, Rubens FD. Cardiopulmonary bypass. In: Sellke FW, Nido PJ \& Swanson SJ. Eds. Sabiston \& Spencer Surgery of the Chest. 9th ed. Philadelphia: Elsevier Science, Inc, 2016:1071-1093.
8. Ghali WA, Quan H \& Shrive FM. Outcomes after coronary artery bypass surgery In Canada. 1992/93 to 2001/01. Can J Cardiol 2003; 19: 774-781.

9. Greenbarg MD, Katz NM, Luliano S, Tempesta BJ, Solomon AJ. Cardiac Rhythm Disturbance. In: Kouchoukos NT, Blackstone EH, Hanley FL, Kirklin JK. Eds. Kirklin/Barratt-Boys Cardiac Surgery. 4th ed. Philadelphia: Elsevier Saunders, Inc, 2013: 698-741.

10. Legare JF, Buth KJ, King S, Wood J, Sullivan JA, Friesen $\mathrm{CH}$, et al. Coronary bypass surgery performed off pump does not result in lower in-hospital morbidity than CABG performed on pump. Circulation 2004; 109:887-892.

11. Bull DA, Neumayer LA, Stringham JC, Affleck DG, Karwande SV, Meldrum P, et al. Coronary artery bypass grafting with cardiopulmonary bypass versus off-pump cardiopulmonary bypass grafting: Does eliminating the pump reduce morbidity and cost? Ann Thorac Surg 2001; 71: $170-175$

12. Galloway AC, Shemin RJ, Glower DD, Groh MA, Kuntz RE, Burdon TA. First report of the port Access International Registry. Ann Thorac Surg 1999; 67(1): 5158.

13. Cartier R, Brann S, Dagenais F, Martineau R, Couture A. Systematic off-pump Coronary artery revascularizartion in multivessel diseases. J Thorac Cardiovase Surg 2000; 119(2): 221-229.

14. Cafiore AM, Teodri G, Mezzetti A, Bosco G, Verna AM. Intermittent Antegrade Warm Blood Cardioplegia. Ann. Thorac Surg 1995; 59(2): 398-402.

15. Ahmed N, Rashid Z, Zulkanaine I, Hasan A, Adhikary A, Alimuzzaman M, et al. Comparative Study of Coronary Bypass Surgery on Beating Heart and Cardiopulmonary Bypass. Bangladesh Heart Journal 1998; 13: 21-24.

16. Cleveland JC, Shroyer ALW, Chen AY, Peterson E, Grover FL. Off-pump coronary artery bypass grafting decreases risk-adjusted mortality morbidity. Ann Thorac 2001; 72:1282-1289.

17. Hasse M, Sharma MK, Fielitz A, Uchino S, Rockteschel I, Bellomo R, et al. On-pump coronary artery bypass surgery versus off-pump exclusive arterial coronary grafting: a matched cohort comparison. Ann Thorac Surg 2003; 75: 62-67.

18. Hazelrigg SR, Boley TM, Cetindag IB, Moulton KP, Trammell GL, Polancic JEet al. The efficacy of supplemental magnesium in reducing atrial fibrillation after coronary artery bypass grafting. Ann Thorac Surg 2004; 77(3):824-830.

19. Boyd WD, Desai ND, Rizzo DF, Novick RJ, Mckenzie FN and Menkis AH. Off-Pump Surgery Decreases Postoperative Complications and Resource Utilization. Ann Thorac Surg 1999; 68: 1490-1493.

20. Ascione R, Lloyd TC, Underwood JM, Lotto AA, Pitsis AA, Angiline DG. Economic Outcome of Off-Pump Coronary Artery Bypass Surgery: A prospective Randomized Study. Ann Thorac Surg 1999; 68: 2237-2242.

21. Shennib H. Endo M, Benhamed O, Morin JF. Surgical revascularization in patients with poor left ventricular function on -pump or off- pump. Ann Thorac Surg 2002; 74:1344-1347.

22. Hoff SJ, Ball SK, Colthrap WH, Glassford DM, Lea JW,Petracek MR. Coronary artery bypass in patients of 80 years and over is off-pump the operation of choice? Ann Thorac Surg 2002; 74: S1340-S1343. 